\title{
Anakoinosis: Communicative Reprogramming of Tumor Systems - for Rescuing from Chemorefractory Neoplasia
}

\author{
Christina Hart $^{1}$ - Martin Vogelhuber ${ }^{1} \cdot$ Daniel Wolff $^{1} \cdot$ Sebastian Klobuch $^{1}$. \\ Lina Ghibelli ${ }^{2}$. Jürgen Foell ${ }^{3}$ Selim Corbacioglu ${ }^{3} \cdot$ Klaus Rehe $^{3} \cdot$ Guy Haegeman $^{4}$. \\ Simone Thomas ${ }^{1} \cdot$ Wolfgang Herr $^{1} \cdot$ Albrecht Reichle ${ }^{1,5}$
}

Received: 9 June 2015 / Accepted: 30 June 2015 / Published online: 11 August 2015

(C) The Author(s) 2015. This article is published with open access at Springerlink.com

\begin{abstract}
Disruptive technologies, such as communicative reprogramming (anakoinosis) with cellular therapies in situ for treating refractory metastatic cancer allow patient care to accelerate along a totally new trajectory and highlight what may well become the next sea change in the care of patients with many types of advanced neoplasia. Cellular therapy in situ consisted of repurposed drugs, pioglitazone plus all-trans retinoic acid or dexamethasone or interferon-alpha (dual transcriptional modulation) combined with metronomic low-dose chemotherapy or low-dose 5-azacytidine, plus/minus classic targeted therapy. The novel therapeutic tools for specifically designing communication processes within tumor diseases focus on redirecting (1) rationalizations of cancer hallmarks (constitution of single cancer hallmarks), (2) modular events, (3) the 'metabolism' of evolutionary processes (the sum of therapeutically and intrinsically inducible evolutionary processes) and (4) the holistic communicative context, which determines validity and denotation of tumor promoting communication lines. Published data on cellular therapies in situ (6 histologic tumor types, 144 patients, age $0.9-83$ years) in
\end{abstract}

Albrecht Reichle

albrecht.reichle@ukr.de

1 Department of Internal Medicine III, Haematology \& Oncology, University Hospital of Regensburg, Regensburg, Germany

2 Department of Biology, Universita' di Roma Tor Vergata, Rome, Italy

3 Department of Pediatrics, University Hospital of Regensburg, Regensburg, Germany

4 University Gent, Ghent, Belgium

5 Department of Internal Medicine III, Hematology and Oncology, University Hospital of Regensburg, Franz-Josef-Strauss-Allee 11, 93053 Regensburg, Germany castration-resistant prostate cancer, pretreated renal clear cell carcinoma, chemorefractory acute myelocytic leukemia, multiple myeloma > second-line, chemorefractory Hodgkin lymphoma or multivisceral Langerhans cell histiocytosis, outline the possibility for treating refractory metastatic cancer with the hope that this type of reprogrammed communication will be scalable with minimal toxicity. Accessibility to anakoinosis is a tumor inherent feature, and cellular therapy in situ addresses extrinsic and intrinsic drug resistance, by redirecting convergent organized communication tools, while been supported by quite different pattern of (molecular-)genetic aberrations.

Keywords Communication tools - Transcriptional modulation · Metronomic low-dose chemotherapy · Drug repurposing - Tumor heterogeneity - Cellular therapy in situ . Anakoinosis · Acute myelocytic leukemia · Classic Hodgkin lymphoma $\cdot$ Multiple myeloma $\cdot$ Langerhans cell histiocytosis $\cdot$ Renal clear cell carcinoma $\cdot$ Castration-resistant prostate cancer

\section{Introduction}

Currently proposed cancer models are favoring the selection of theme-dependent therapeutic targets, i.e., tumor-promoting pathways, specific epitopes etc. [1]. Despite the multifold beneficial effects of classic targeted therapies, the underlying cancer models are stretched to their limits if mixed or poor response occurs at metastatic sites, although the respective targets have been diagnostically proven [2].

One limitation of reductionist cancer models is the themedependent attribution of tumor systems objects, i.e., cell compartments, pathologic pathways, oncogenes etc. to distinct tumor features, e.g., hallmarks of cancer, such as 
inflammation, angiogenesis, immune response etc. [3]. Frequently, genetic heterogeneity, just at metastatic sites, limits validity of reductionist cancer models: Situate validity and denotation of tumor systems participators are systems-and stage-dependently highly diversified $[4,5]$.

Additionally, changing compositions of the tumor microenvironment during tumor progression and metastatic spread suggest stage-dependent diversification of processes supporting hallmarks of cancer, so called rationalizations $[6,7]$. The situate diversity and redundancy of such rationalizations leads to the assumption that we cannot precisely predict in developing systems, such as in tumors, the situate validity and denotation of single systems objects, i.e., cells, pathways, and therapeutic targets etc. without administering novel read-out technologies describing their situate functionality [8].

Insufficient treatment response based on reductionist derived tumor models, leads to revising underlying hypotheses. The importance of alternative therapy models may be proven by systematically designing treatment approaches for chemorefractory metastatic tumor diseases. 'Cellular therapies in situ' are representing such novel approaches.

Primary aim of cellular therapies in situ is the communicative reprogramming of tumor systems (anakoinosis) for diversifying palliative care, moreover, for uncovering novel ways for the induction of tumor cell death. Cellular therapies in situ comprise repurposed drugs $[9,10]$ with poor monoactivity, but concerted regulatory activity, such as transcriptional modulators (dual transcriptional modulation) [11-13], metronomic lowdose chemotherapy [14], and classic targeted therapies [9].

The theoretical, communication based background has been derived from phase II trials on cellular therapies in situ, summarized in the 'principles of modular tumor therapy' $[15,16]$. Cellular therapies in situ have the capacity for rededicating functions and identities of cellular compartments or tumor-promoting pathways, thereby attenuating tumor growth (anakoinosis) without directly knocking down tumor-promoting pathways or single cell compartments.

The summary on studies using cellular therapies in situ impressively shows, to our knowledge for the first time, that anakoinosis reproducibly mediates diversified novel systems behaviors in chemorefractory tumors, and that communicative reprogramming is able to depict and categorize targetable communication tools in refractory tumor systems.

\section{Material and Methods}

For presenting tumor-associated communication tools as valid therapeutic targets in systemically pretreated, refractory metastatic cancers or hematologic malignancies, we summarized published clinical trials or compassionate use approaches, which uniquely introduced cellular therapies in situ.
The single components of cellular therapies in situ are showing concerted regulatory activity, why toxicity can be saved [16]. Cellular therapies in situ, presented here, consisted of two major components, dual transcriptional modulation [11-13] combined with drugs, which may enhance the activity profile of transcriptional modulators, i.e., metronomic lowdose chemotherapy (angiostatic, immune modulatory) [14] or low-dose 5-azacytidine (epigenetic reprogramming). A third component was added in some trials, namely classic targeted therapies (imatinib, COX-2 inhibitors, lenalidomide and mTor-inhibitors), again in a drug repurposing manner to intensify the angiostatic, anti-inflammatory, and immune modulatory activity profile (Table 1$)[9,10]$.

Dual Transcriptional Modulation Ligands of nuclear receptors (NR) cue signaling response, establish ligand- nuclear receptor links to transcription- and signal transduction layers, induce gene expression changes, modulate cell type- and ligand-dependent cell fate transitions [17] and finally - so the present hypothesis - propose differential tumor- and involved organ response.

At the cell level, cell fate transitions comprise the regulation of a plethora of gene programs including, among others, regulation of cell proliferation, metabolism and specific functionalities that are acquired by differentiated cells. While the early steps of NR function and their impact on organ physiology is well understood, little is known about the dynamic gene networks that ultimately cause or modulate a particular pathophysiological phenomenon, e.g., a hallmark of cancer, supported by respective NR ligands/hormones in tumor tissues. Therapeutic dual transcriptional modulation aims at reprogramming communication tools in tumor tissues for attenuating tumor growth $[11-13,17]$.

Communicative Reprogramming To fill the gap in our understanding of cellular therapies in situ, particularly, on the activity profile of transcriptional modulators in complex tissue organizations, we operationalized the proposed communicative reprogramming of tumor tissues according to classifiable clinical phenomena arising during cellular therapies in situ.

Although, the systematization of tumor-associated communication tools is already a result of clinical observations during and after cellular therapies in situ, we introduce these tools upfront to present the respective clinical observations clearly arranged $[15,16]$.

The novel therapeutic tools for specifically designing communicative reprogramming (anakoinosis) focus on four topics [15], on redirecting (1) rationalizations of cancer hallmarks (the diverse physical constitutions of single cancer hallmarks) [18], (2) modular events (changing validity and denotation of systems objects) [19], (3) the 'metabolism' of evolutionary processes (the sum of extrinsically, i.e., therapeutically, and intrinsically inducible evolutionary processes within the 
tumor compartment) and (4) the holistic communicative context of structures, functions, decision maxims, i.e., hubs, in the tumor compartment, which finally determines validity and denotation of tumor promoting communication lines.

Phase I/II Trials and Compassionate Use Therapies Altogether, 144 patients (age ranging from 11 months to 83 years) suffering from six histologically different tumor types were treated in three published phase II trials, one phase I trial, and three compassionate use therapies (two already published) and are now available for studying response behavior to cellular therapy in situ: Two published phase II trials on metastatic renal clear cell carcinoma (RCCC), trial II ( $n=31,33$ patients for intent-to-treat analysis) including pioglitazone and interferon-alpha; trial I ( $n=18$ ) including pioglitazone, serves as historic control [20]; two published trials on castrationresistant prostate cancer CRPC I $(n=38)$; CRPC II $(n=61)$ $[21,22]$, differing in the metronomically administered cytotoxic drug, capecitabine (CRPC I) versus treosulfan (CRPC II), and in an additional targeted therapy, imatinib (CRPC II); one published phase I part of an on-going phase II trial for multiple myeloma (MM, phase I, $n=6,>=$ third line therapy, retreatment with lenalidomide after IMiD failure was allowed) [23], and two already published retrospective evaluations (compassionate use) of patients with acute myelocytic leukemia (AML, $n=5$ ) refractory to standard induction chemorefractory [24], or chemo- and brentuximabvedotin-refractory classic Hodgkin lymphomas (cHL, $n=3$, forth-line therapy) [25], and one, yet unpublished, pediatric compassionate use therapy for chemorefractory multivisceral Langerhans cell histiocytosis (third line therapy in $\mathrm{mLCH}, n=2$ ) in analogy to recently published data on $\mathrm{mLCH}[26,27]$.

The two consecutive eighteen and 11 months old children (girl/boy) with chemorefractory $\mathbf{m L C H}$ were treated after informed consent by their parents on compassionate-use basis as indicated in Tables 1 and 2. Treatment was performed in the absence of alternative therapeutic options outside a clinical trial and without formal institutional review board approval.

Some important activity profiles of anakoinosis inducing regimens could be only shown after withdrawal of patients from study due to developing resistance (CRPC II trial, $n=10$ ); or non-oncologic surgical interventions (knee or hip replacement in CRPC II trial, $n=6)$ in case of preceding prostate specific antigen response (PSA in serum $<4 \mathrm{ng} / \mathrm{mL}$ ). The surgical patients, all having rapidly progressive disease at study inclusion (PSA doubling time $<3$ months), were followed without any tumor specific therapy, except bisphosphonates, until PSA doubling. Ten patients with CRPC were additionally treated with a gonadotropin-

Table 1 Anakoinosis: designing evolutionary processes in tumor tissues and exploiting and operationalizing their scope with cellular therapies in situ

Cellular therapy in situ

Anakoinosis: Designing evolutionary processes in tumor tissues and exploiting and operationalizing their scope

\begin{tabular}{|c|c|c|c|}
\hline \multirow{2}{*}{$\begin{array}{l}\text { Drug repurposing for communication } \\
\text { design }\end{array}$} & \multicolumn{3}{|c|}{ Anakoinosis promoting therapeutic tools: 'Top down' strategies } \\
\hline & $\begin{array}{l}\text { Dual transcriptional } \\
\text { modulation }\end{array}$ & $\begin{array}{l}\text { Metronomic low- } \\
\text { dose } \\
\text { chemotherapy }\end{array}$ & Classic targeted therapy \\
\hline $\begin{array}{l}\text { Communication derived tools for } \\
\text { evolving tumor systems }\end{array}$ & $\begin{array}{l}\text { Evolving tumor systems } \\
\text { - Targets are ubiquitously } \\
\text { distributed among tumor, } \\
\text { stroma and organ cells; } \\
\text { - Stimulating, not blocking }\end{array}$ & $\begin{array}{l}\text { Modulation of } \\
\text { - Angiogenesis, } \\
\text { immune } \\
\text { response, } \\
\text { inflamation; } \\
\text { - Cell type } \\
\text { dependent } \\
\text { biomodulatory } \\
\text { activity }\end{array}$ & $\begin{array}{l}\text { Drug repurposing } \\
\text { - Novel activity profile of targeted therapies } \\
\text { in the biomodulatory context; } \\
\text { - Pleiotropic novel activities }\end{array}$ \\
\hline $\begin{array}{l}\text { - Targeting rationalizations of cancer } \\
\text { hallmarks } \\
\text { - Targeting modular events } \\
\text { - Targeting the 'metabolism' of } \\
\text { evolutionary processes } \\
\text { - Targetring the holistic communicative } \\
\text { context by implementation of non- } \\
\text { normative boundary conditions }\end{array}$ & $\begin{array}{l}\text { - Pioglitazoine (Actos) } \\
45 \mathrm{mg} \text { p.o. daily } \\
\text { - All-trans retenoic acid } \\
45 \mathrm{mg}^{2} \text { p.o. daily } \\
\text { - Interferon alpha } 3 \mathrm{MU} \text { s.c. } \\
\text { three times a week } \\
\text { Pioglitazone (Actos) } 60 \mathrm{mg} \\
\text { p.o. daily } \\
\text { - Pioglitazone (Actos) } \\
60 \mathrm{mg} \text { p.o. daily } \\
\text { Dexamethasone } 0.5 \text { to } \\
1.0 \mathrm{mg} \text { daily }\end{array}$ & $\begin{array}{l}\text { - Treosulfan } 250 \mathrm{mg} \\
\text { twice daily } \\
\text { - Trofosfamide } \\
50 \mathrm{mg} \text { thrice } \\
\text { daily } \\
\text { - Capecitabine } 1 \mathrm{~g} \\
\text { twice daily } \\
\text {-5-azacytidine } \\
75 \mathrm{mg} \text { absolute } \\
7 \text { days, every } \\
4 \text { weeks }\end{array}$ & $\begin{array}{l}\text { - Low-dose lenalidomide (after lenalidomide failure) } \\
15 \mathrm{mg} \text { p.o. daily } \\
\text { - Imatinib } 400 \mathrm{mg} \text { p.o. daily } \\
\text { - mTor inhibitor (in Hodgkin lymphoma, everolimus, } \\
\text { serum level } 15 \mathrm{ng} / \mathrm{ml} \text {; in multivisceral Langerhans } \\
\text { cell histiocytosis, temsirolimus weight-adapted } \\
\text { in child) } \\
\text { - COX-2 inhibitor etoricoxib } 60 \mathrm{mg} \text { p.o. daily or } \\
\text { rofecoxib } 25 \mathrm{mg} \text { daily }\end{array}$ \\
\hline
\end{tabular}


Table 2 Cellular therapies in situ (trials and compassionate use programs) in pretreated or refractory hematologic malignancies or metastatic tumors

\begin{tabular}{|c|c|c|c|c|c|c|c|}
\hline & Cellular therapy in situ & & & & & & \\
\hline Neoplasia & Therapy-line & No & $\begin{array}{l}\text { Metronomic } \\
\text { chemotherapy }\end{array}$ & $\begin{array}{l}\text { Transcriptional } \\
\text { modulator }\end{array}$ & $\begin{array}{l}\text { COX-2 } \\
\quad \text { inhibitor }\end{array}$ & Small molecule & Publication \\
\hline $\begin{array}{l}\text { Renal clear cell carcinoma, } \\
\text { Phase II (RCCCI) }\end{array}$ & $\begin{array}{l}\text { Unlimited number of } \\
\text { previous systemic } \\
\text { therapies }\end{array}$ & 18 & Capecitabine & Actos & $\begin{array}{l}\text { COX-2 } \\
\quad \text { inhibitor }\end{array}$ & - & $\begin{array}{l}\text { Biomarker Insights, } \\
2006\end{array}$ \\
\hline $\begin{array}{l}\text { Renal clear cell carcinoma, } \\
\text { Phase II, (RCCCII) }\end{array}$ & $\begin{array}{l}\text { Unlimited number } \\
\text { of previous systemic } \\
\text { therapies }\end{array}$ & 45 & Capecitabine & $\begin{array}{l}\text { Actos, } \\
\text { IFNalpha }\end{array}$ & $\begin{array}{l}\text { COX-2 } \\
\text { inhibitor }\end{array}$ & - & World J Urol, 2002 \\
\hline $\begin{array}{l}\text { Prostate cancer Phase II, } \\
\text { (CRPC II) } \\
\text { ClinicalTrilas.gov, } \\
\text { NCT00427999 }\end{array}$ & $\begin{array}{l}\text { Castration-resistant, } \\
<3 \text { months PSA } \\
\text { doubling-time in } \\
77 \%\end{array}$ & 61 & Treosulfan & Actos, Dexa & $\begin{array}{l}\text { COX-2 } \\
\text { inhibitor }\end{array}$ & Imatinib & $\begin{array}{l}\text { Cancer } \\
\text { Microenvironm. } \\
2014\end{array}$ \\
\hline $\begin{array}{l}\text { Prostate cancer, } \\
\text { Phase II (CRPC I) }\end{array}$ & Castration-resistant & 36 & Capecitabine & Actos, Dexa & $\begin{array}{l}\text { COX-2 } \\
\text { inhibitor }\end{array}$ & - & $\begin{array}{l}\text { World J Urol. } 2013 \\
\text { Lancet Oncology, } \\
2006\end{array}$ \\
\hline $\begin{array}{l}\text { Langerhans cell } \\
\text { histiocytosis, } \\
\text { multivisceral } \\
\text { (compassionate use) }\end{array}$ & $\begin{array}{l}\text { Third-line, } \\
\text { chemorefractory }\end{array}$ & 2 & Trofosfamide & Actos, Dexa & $\begin{array}{l}\text { COX-2 } \\
\text { inhibitor }\end{array}$ & $\begin{array}{l}-/+ \\
\quad \text { Temsirolimus }\end{array}$ & $\begin{array}{l}\text { Br. J. Haematol, } \\
\quad 2005\end{array}$ \\
\hline $\begin{array}{l}\text { Classic Hodgkin lymphoma } \\
\text { (compassionate use) }\end{array}$ & $\begin{array}{l}\text { Forth-line, } \\
\text { chemorefractory }\end{array}$ & 3 & Treosulfan & Actos, Dexa & $\begin{array}{l}\text { COX-2 } \\
\text { inhibitor }\end{array}$ & Everolimus & $\begin{array}{l}\text { Br. J. Haematol, } \\
2015\end{array}$ \\
\hline $\begin{array}{l}\text { Acute myelocytic leukemia } \\
\text { (compassionate use) }\end{array}$ & $\begin{array}{l}\text { Refractory to standard } \\
\text { induction } \\
\text { chemotherapy }\end{array}$ & 5 & 5-azacytidine & $\begin{array}{l}\text { Actos, } \\
\text { Vesanoid }\end{array}$ & - & - & $\begin{array}{l}\text { Haematologica, } \\
2014\end{array}$ \\
\hline $\begin{array}{l}\text { Multiple myeloma Phase } I \\
\text { ClinicalTrials.gov, } \\
\text { NCT001010243 }\end{array}$ & $\begin{aligned}>= & 3 \text { rd-line } \\
& \text { pretreatment } \\
& \text { with lenalidomide }\end{aligned}$ & 6 & Treosulfan & Actos, Dexa & - & Lenalidomide & $\begin{array}{r}\text { Blood 2012; } \\
120: 5029\end{array}$ \\
\hline
\end{tabular}

releasing hormone $(\mathrm{GnRH})$ agonist, leuprorelinacetate, after developing resistance to cellular therapy in situ, despite the preceding resistance to $\mathrm{GnRH}$ agonists.

\section{Redirecting Rationalizations of Cancer Hallmarks}

Rationalizations in the present context describe the multifold physical constitutions of single hallmarks of cancer [18]. The constitution of rationalizations comprises multiple and, if pathophysiologically required, exchangeable tumor cell compartments (redundancy) [28].

The following rationalizations for hallmarks of cancer were clinically monitored:

- Inflammation response in serum: In RCCC ( $\mathrm{RCCC}$ trial I, II), mLCH and MM inflammation control was defined as a $>30 \%$ decrease of C-reactive protein from base-line [20, 23]. In cHL a normalization of CRP levels was considered critical as clinically relevant inflammation response [25].

- In CRPC we followed immune response in one patient with tumor-associated (paraneoplastic) lupus erythematosus (CRPC I) [29].

The specific constitution of rationalization processes, such as inflammation can be shown by inflammation control following specific dual transcriptional modulation (Tables 1 and 2):

- $\quad$ In the RCCC II trial pioglitazone was supplemented by low-dose interferon-alpha three times a week (Tables 1 and 2). Inclusion criteria in RCCC trial I, II were identical; therefore, a historic comparison of PFS and OS is possible [20].

- In a 2 years old boy with chemorefractory multivisceral Langerhans cell histiocytosis and insufficient inflammation control (fever) with pioglitazone / dexamethasone besides metronomic low-dose chemotherapy, temsirolimus was added in an adoptive therapy design in analogy to the therapy schedule for cHL.

- Heterogeneity of response to anakoinotic therapy: In the CRPC II trial PSA response was presented in waterfall plots to depict therapy sensitivity and resistance of single tumors [22].

\section{Rearranging Modular Structures}

Communication technically, cells are artifacts with situate varying cellular identities and communication tools. Modularity - in a novel definition - describes the degree and specificity to which systems' objects, i.e., cells, pathways, 
molecules, therapeutic targets etc. may be communicatively rededicated by anakoinosis that means, how they alter their validity and denotation in the systems context $[15,16]$.

Objective response of multiple pretreated, chemo- or castration-resistant tumor diseases to cellular therapy in situ may be achieved by modular events, that means without specifically targeting any tumor promoting pathway, but by communicatively rededicating validity and denotation of tumor-promoting systems objects.

- Progression-free survival (PFS) was the primary endpoint of all prospective trials and was also studied in the compassionate use projects.

- For CRPC I, II and RCCC I, II also survival data are available [20-22].

- Tumor, leukemia and lymphoma cell death:

- Histopathological evaluation of complete remission (CR in bone, lung) could be performed in RCCC II [20].

- Molecular CR (CRm) in AML: Leukemia cell death could be monitored by morphology and polymerase chain reaction (PCR) studies for molecular-genetic markers of AML blasts at diagnosis [24].

- Histologic evaluation was possible at all metastatic sites in both children with $\mathrm{mLCH}$.

- Histologic and serologic confirmation of CR (serum and urine) in MM [23].

- Disease chronification at minimal residual disease (prostate-specific antigen, PSA $<4.0 \mathrm{ng} / \mathrm{mL}$ ) was studied in CRPC II.

- Delayed response (partial remission, PR after $>4$ months) in RCCC II and rapid response ( $<=4$ cycles, correspondingly 4 months) was monitored in chemorefractory cHL and AML [20, 24, 25].

\section{Therapeutically Mediated Diversification of Evolutionary Tools in the Tumor}

The specific 'metabolism' of evolutionary processes in a tumor may be considered as the sum of intrinsically and therapeutically, via anakoinosis inducible evolutionary processes within the tumor compartment.

Intrinsically occurring tumor-associated evolutionary processes are characterized by the acquisition of moleculargenetic heterogeneity $[30,31]$. Cellular therapy in situ claims to externally induce evolutionary processes via communicative reprogramming of cellular tumor compartments. Therefore, novel tumor systems behaviors may be clinically expected following induction of anakoinosis:
- Induction of biological memory means that tumor regrowth is significantly delayed in comparison to the corresponding rapid progression at study inclusion (PSA doubling time $<3$ months), although study medication was withdrawn due to non-tumor related surgery. In CRPC II, PSA doubling time prior to study inclusion has been routinely studied.

- Restoration of hormone-sensitivity in CRPC was monitored following development of resistance to study medication by the add-on of leuprorelinacetate, while continuing study medication.

- Further, sites of tumor response in RCCC II, cHL, and $\mathrm{mLCH}$ were monitored. These observations give hints, whether therapy response can be established at all metastatic sites, despite the suggested molecular-genetic tumor heterogeneity at metastatic sites.

- At relapse or progression, metastatic sites were routinely monitored in the RCCC II trial to study, whether anakoinotic therapy approaches may attenuate metastatic spread [20].

- Molecular-genetic heterogeneity and induction of anakoinosis: In AML, response could be correlated with respective molecular-genetic aberrations at diagnosis [24].

- Differentiation response: In AML we studied granulocytes for molecular-genetic aberrations found in AML blasts at diagnosis [24].

- Patients with CRPC and lymph node metastases (CRPC II) were routinely screened for objective response with $\mathrm{CT}$ scans [22].

\section{Holistic Communicative Context in the Microenvironment Determining Specific Pathologies}

Tumor diseases are specified by characteristic tumor histologies which arise on the basis of likewise tumorspecific communication tools, operating among tumor cells, their corresponding stromal surroundings and the respective organ site. Cellular therapies in situ, as topdown strategies interfere with those specific communication tools of a tumor, which are suggested to be holistically organized for constituting typical tumor-stromaorgan interactions.

Holistic communicative conditions require a communication-derived assessment of systems participators from the participator's view: That means communication with a neighboring cell compartment in a tumor may not only alter validity and denotation of the addressee, but simultaneously of the addressor from the point of view of the addressee [15].

Therefore, monitoring biologic aspects of tumor response should uncover novel cytological or histological rearrangements or imaging technical behaviors (PET scan, bone 
scan) depicting reciprocal communicative interactions within tumor-stroma-organ compartments [22, 25].

In case of AML and MM bone marrow cytology and blood count provide insights in communicative interactions of leukemia cells and normal hematopoiesis [23, 24].

In Hodgkin disease, metabolic activity in the lesions (PET scan) could be correlated with CRP response in serum [25].

In the children with $\mathbf{m L C H}$ restoration of severely altered organ functions could be monitored, in RCCC and CRPC the CT-morphological behavior of osteolytic and osteoplastic metastases, respectively.

In CRPC II, technetium up-take in bone lesions was monitored by technetium scans during PSA response [22].

\section{Safety and Quality of Life}

For all patients safety data are available and already published, except in case of $\mathrm{mLCH}(n=2)$. Data are given in the present paper.

In CRPC data on quality of life during the first 6 months on cellular therapy in situ are available [22].

\section{Results}

\section{Modulation of the Tool of Rationalizations Constituting Hallmarks of Cancer}

Inflammation Control A limited pattern of hallmarks of cancer could be clinically monitored, such as inflammation, via CRP response, in RCCC I/II $(n=18 ; n=31)$ (Fig. 1), in $\mathrm{MM}(n=6)$ and $\mathrm{mLCH}(n=2)$, immune response in one patient with CRPC (CRPC I) (Fig. 2).

Specification of anti-inflammatory therapy in RCCC II by the add-on of low-dose interferon-alpha (Table 2) led to a significant decline of CRP levels in serum, to a significantly improved PFS and a tendency to improved OS in comparison to the respective historical control group, receiving pioglitazone alone (RCCC I) (Fig. 1) [22, 32-34].

In MM response (long-term stable disease, partial remission, very good partial remission and CR) was associated with $>30 \%$ CRP decrease $(n=6)$ [23].

In cHL the CRP levels rapidly normalized $(n=2)$ and PET negativity ensues at quite different metastatic sites, in lymph nodes, bone and lung lesions. One patient has shown no elevated serum CRP levels at study inclusion, but also achieved continuous complete remission cCR [25]. Long-term cCR

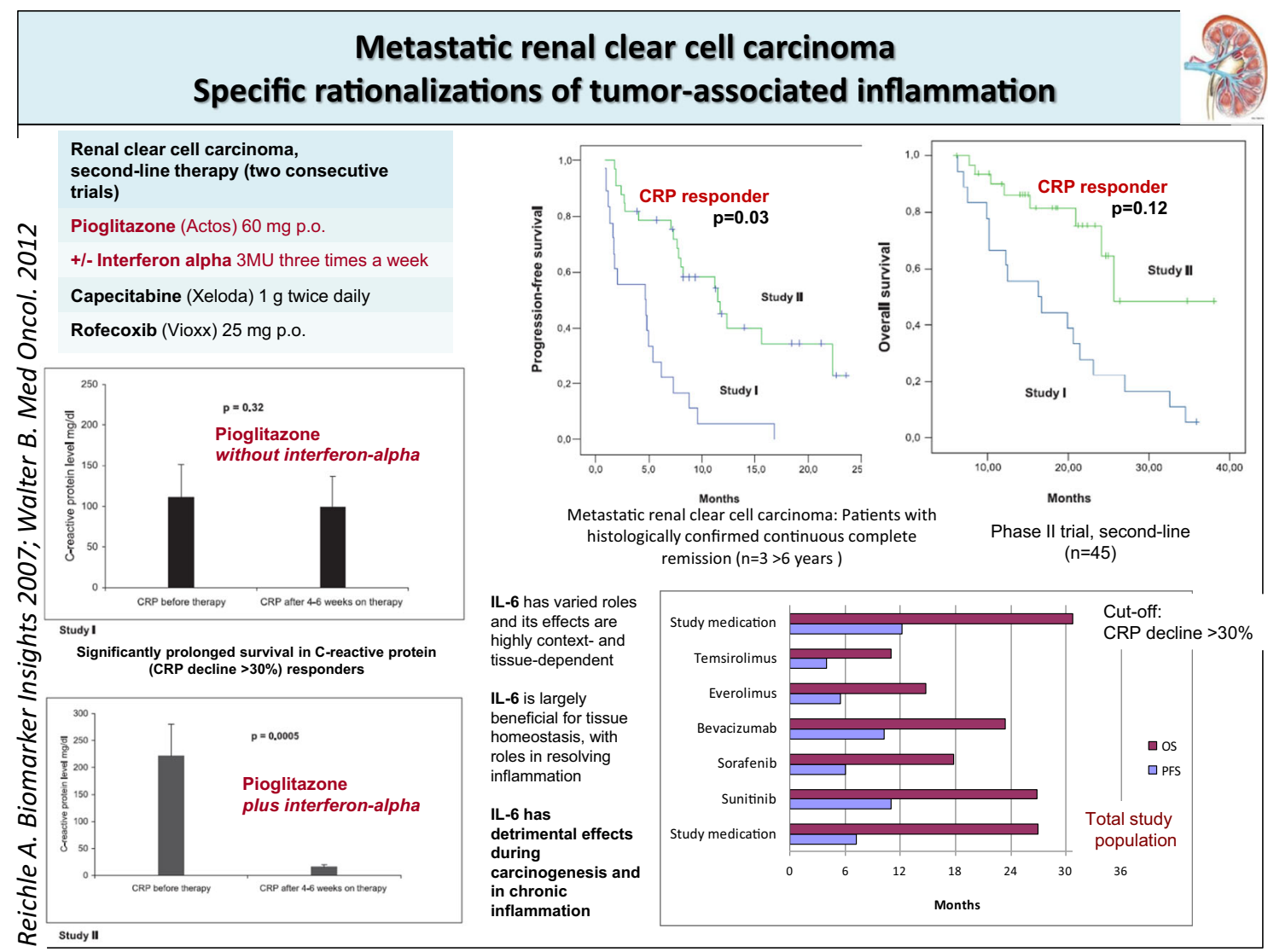

Fig. 1 The addition of interferon-alpha to pioglitazone in pretreated renal clear cell carcinoma is associated with inflammation control, improved PFS and OS in comparison with a historical control. PFS and OS data compare with those achieved in first-line with standard therapies 


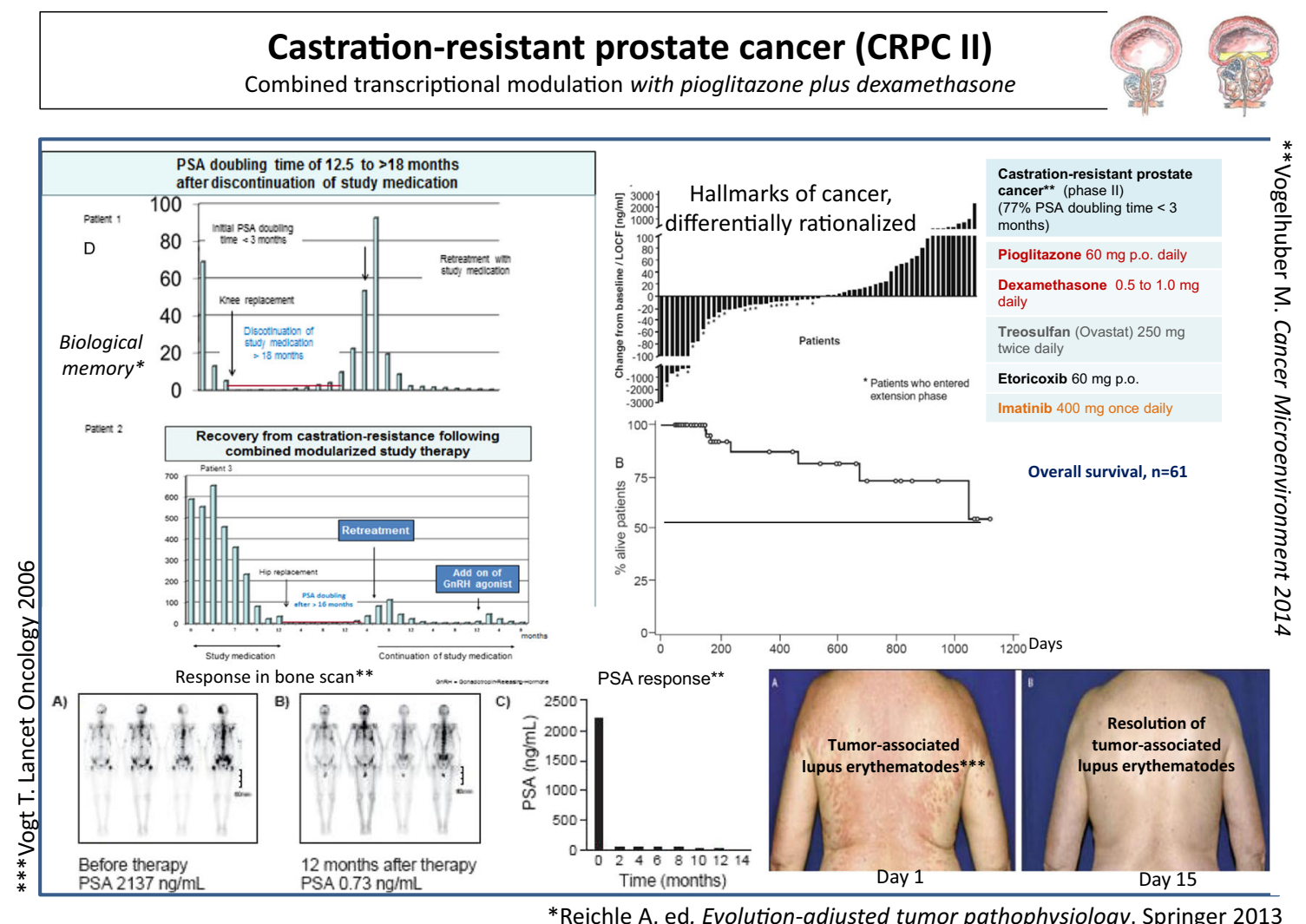

Fig. 2 A In the CRPC II trial, median OS has not been achieved after 3 years, although $39 \%$ of the patients did not show objective response ( $>50 \%$ PSA response) to cellular therapy in situ. B Response in bone scan was observed in six of six patients. C Control of paraneoplastic lupus erythematosus was associated with objective tumor response. D Therapy

was observed in two of three patients with cHL following allogeneic blood stem cell transplantation.

In $\mathbf{m L C H}, \mathrm{CRP}$ levels normalized in response to compassionate use therapy (Fig. 3) [25].

Immune Response Resolution of a tumor-accompanying systemic lupus erythematosus occurred in CRPC I $(n=1)$ within 14 days on treatment with study drugs. Immune response was paralleled with objective tumor response (Fig. 2) [29].

Communication Tools, Available for Induction of Anakoinosis may be Heterogeneous within a Histologically Defined Tumor Type Waterfall plots for PSA response in the CRPC trial II (Fig. 2) indicate differential sensitivity of cellular therapy in situ: A percentage of $39 \%$ CRPC patients did not respond to cellular therapy in situ (PSA decline in serum $<50 \%$ ), nevertheless OS for the total patient population is nearly doubled compared to standard docetaxel therapy [22].

mLCH In a 18 months old girl with chemorefractory multivisceral LCH, weight-adapted metronomic low-dose response was on-going in six patients beyond stop of study medication ( 5 to 18 months) due to non-oncologic surgery. Following resistance to cellular therapy in situ, $60 \%$ of the studied patients regained responsiveness against gonadotropin-releasing hormone $(\mathrm{GnRH})$ agonists

chemotherapy plus pioglitazone and dexamethasone induced cCR (1 year+) in third-line (Fig. 3).

Only the adoptive change to pioglitazone/ dexamethasone plus temsirolimus, besides metronomic low-dose chemotherapy in third-line successfully resolved tumor-associated fever in a $\mathbf{1 1}$ months old boy with chemorefractory $\mathrm{mLCH}$, resulting in histologically proven $\mathrm{cCR}(2$ years +$)$. The successful therapeutic adoption indicates that inflammation/ angiogenesis and immune response may be differentially rationalized within $\mathrm{mLCH}$ diseases [26].

\section{Therapeutically Exploiting Modular Events}

The communicatively induced rededication of validity and denotation of tumor-associated systems participators led to objective responses in refractory (AML, $\mathrm{cHL}, \mathrm{mLCH}, \mathrm{MM}$ ) or repetitively progressive malignant diseases, i.e., in patients with CRPC (77 \% PSA doubling time $<3$ months) [22], and patients with RCCC (RCCC II) [20].

Long-term chronification of CRPC with follow-up of $>4$ to 6 years on therapy is possible $(n=6)$, also in MM ( $>3$ years VGPR, $n=1$ ). 


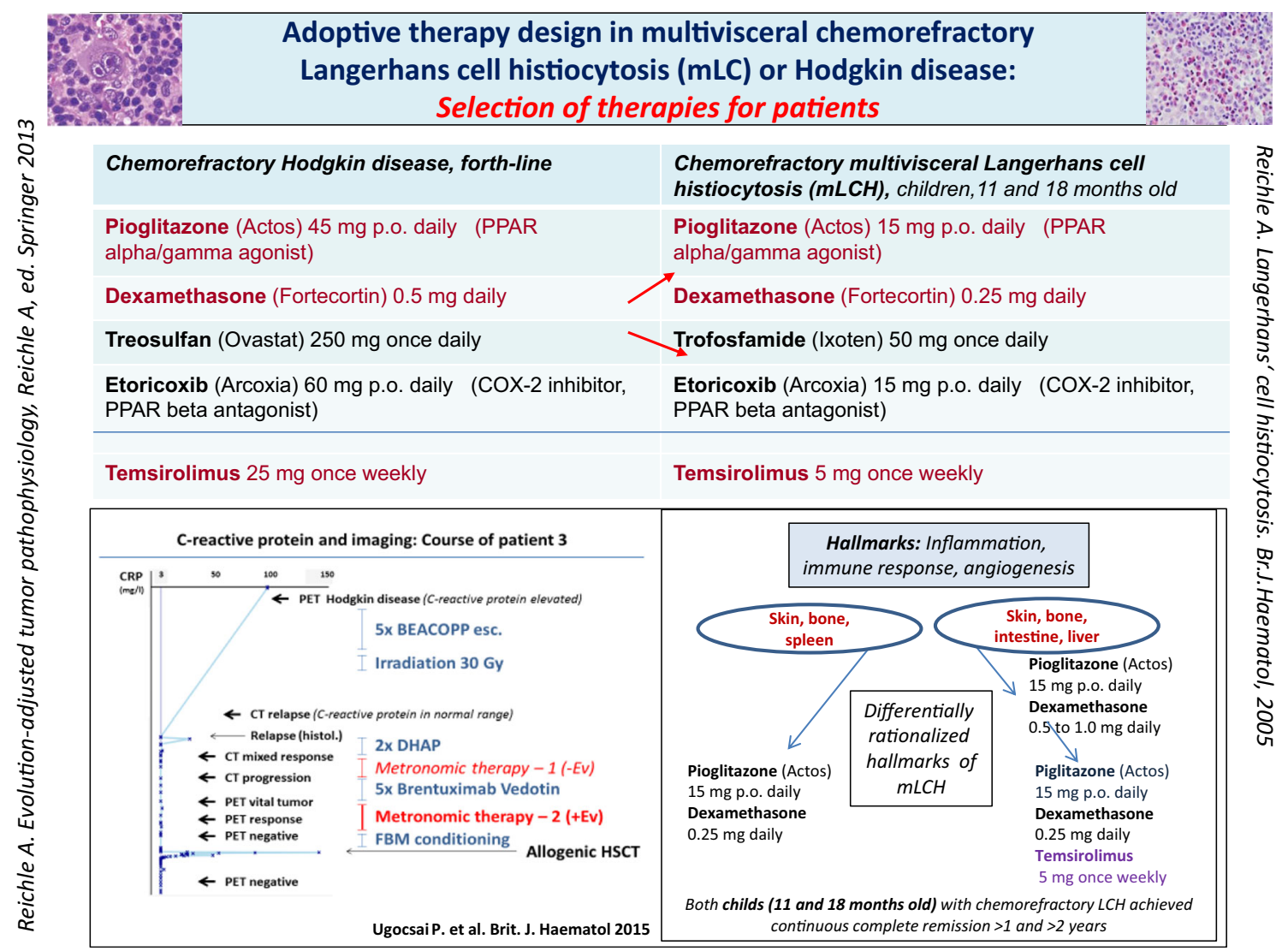

Fig. 3 Left site showing C-reactive protein (CRP) follow-up during chemo- and brentuximab-vedotin refractory cHL. The add-on of everolimus to combined transcriptional modulation with pioglitazone and dexamethasone plus metronomic low-dose chemotherapy led to PET negativity and continuous CR following allogeneic blood stem cell transplantation. The right site indicates that chemorefractory $\mathrm{mLCH}$ may respond with cCR following cHL-therapy without everolimus. But patient two with chemorefractory $\mathrm{mLCH}$ needed the add-on of temsirolimus to achieve cCR

doubling time $<3$ months before study inclusion. The median OS for standard therapy with docetaxel is 19 months [35].

Survival in Pretreated Patients with RCCC (RCCC II) Compares with Historic Controls Treated in First-Line with Standard Therapies Median overall survival at 3 years was $5 \%$ in RCCC trial I versus $48 \%$ in RCCC II, which compares with first-line OS rates to standard therapies (Fig. 1) [20].

\section{Targeting the Specific Metabolism of Evolutionary Processes}

Cellular therapy in situ enables induction of qualitatively novel tumor systems' behaviors, as exemplarily shown by induction of differentiation in non-acute promyelocytic leukemia (non-APL) patients $(n=2)$ [24]; of biological memory (CRPC II, $n=6$ ), and reconstitution of hormone responsiveness in CRPC (six of ten patients), and reduction of the metastatic potential in RCCC II ( 21 of 31 patients, $68 \%$ progression at the original metastatic sites) [16]. 
Table 3 Indicating best responses to cellular therapies in situ

Anakoinosis inducing therapy elements: Dual transcriptional modulation and best response

\begin{tabular}{|c|c|c|c|}
\hline $\begin{array}{l}\text { Transcriptional } \\
\text { modulators }\end{array}$ & Metastatic diseases & Remission induction? Best response & $\begin{array}{l}\text { Add-on of transcriptional modulators/ } \\
\text { repurposed targeted therapies }\end{array}$ \\
\hline $\begin{array}{l}\text { Pioglitazone plus } \\
\text { dexamethasone }\end{array}$ & $\begin{array}{l}\text { - Castration-resistant prostate cancer } \\
\text { - Multiple myeloma (third-line) } \\
\text { - Multivisceral Langerhans cell } \\
\text { histiocytosis (chemo-resistant) } \\
\text { - Hodgkin lymphoma (forth-line) }\end{array}$ & $\begin{array}{l}\text { Minimal residual disease } 6 \text { years }+ \\
\text { First CR in third-line, VGPR } \\
33 \text { months }+ \\
\text { Continuous complete remission } \\
\text { (histologically Confirmed CR) } \\
\text { PET negativity }\end{array}$ & $\begin{array}{l}\text { - Response after lenalidomide failure } \\
\text { - Everolimus } \\
\text { - Temsirolimus }\end{array}$ \\
\hline $\begin{array}{l}\text { Pioglitazone plus } \\
\text { interferon-alpha }\end{array}$ & $\begin{array}{l}\text { - Renal clear cell carcinoma (second- } \\
\text { line) }\end{array}$ & $\begin{array}{l}\text { Continuous complete remission } \\
\text { (Histologically confirmed CR) }\end{array}$ & - Interferon-alpha \\
\hline $\begin{array}{l}\text { Pioglitazone plus all- } \\
\text { trans retinoic acid }\end{array}$ & $\begin{array}{l}\text { - Acute myelocytic leukemia } \\
\text { (refractory) }\end{array}$ & $\begin{array}{l}\text { Continuous complete remission } \\
\text { (molecular CR) }\end{array}$ & $\begin{array}{l}\text { - After 5-azacytidine failure rapid } \\
\text { response }\end{array}$ \\
\hline
\end{tabular}

- Biological memory: Long-term chronification of CRPC (CRPC II) after withdrawal of study medication $(n=6)$ reveals that dual transcriptional modulation may operate evolutionary processes by simultaneously establishing robustness and homeostasis at the novel evolutionary level (biological memory) (Fig. 2). It took 5 to 18 months until PSA doubling. Transcriptionally induced reprogramming of tumor compartments on an epigenetic level seems to play a major role for inducing biological memory.

- Restoration of hormone sensitivity: Six out of ten patients with progressive disease on study medication have shown a more than $50 \%$ PSA response after addition of a gonadotropin-releasing hormone $(\mathrm{GnRH})$ agonist and continuation of study medication.

- Differentiation: A novel phenomenon in AML was a long-lasting 'defect healing' ( $>6$ and 9 months disease stability), characterized by maturation of non-APL blasts in granulocytes with corresponding molecular-genetic aberrations of the blasts $(n=2)$ [24].

Genetic Heterogeneity and Anakoinosis Observations in RCCC II, AML, and cHL, together with the successful adoptive therapy design in $\mathrm{mLCH}$, give hints that

- Cellular therapy in situ may successfully address molecular-genetic heterogeneity at metastatic sites, which is commonly associated with mixed tumor response to classic targeted therapies, by concertedly designing still preserved and uniquely constituted communication tools at metastatic sites: Mixed responses in metastatic RCCC II occurred rarely $(23 \%)$. No mixed responses were observed in $\mathrm{cHL}$ and $\mathrm{mLCH}$ despite the suggested genetic heterogeneity at metastatic sites.

- Despite molecular-genetic and genetic heterogeneity in AML, these patients responded - even though qualitatively different - to a unique therapeutic approach, at best with molecular remission. This observation indicates the presence of convergent evolutionary processes accessible to anakoinosis (Fig. 4) [24].

Targeting the Holistic Communicative Context in the Microenvironment Due to the holistic communicative context in the microenvironment, ,seed and soil' are reciprocally exchangeable as indicated by the implementation of novel communicative reprogramming inducing boundary conditions, i.e., cellular therapy in situ (Fig. 5, Tables 4 and 5). Induction of response via non-theme-dependent targets reveals that the communicative context of reductionist derived structures, functions, and decision maxims, i.e., regulatory acting hubs, are equally important in determining validity and denotation of tumor promoting communication lines as reductionist attributed functions of tumor systems objects.

As a consequence, cellular therapies in situ induce specific functional changes likewise in tumor, adjacent stroma and organ cells:

- Rapid restoration of the involved organ site, e.g., bone marrow, could be achieved in AML with induction failure, in 3 of 5 patients. With the administration of low-dose 5azacytidine, neutrophil counts in the peripheral blood increased at each start of a 4 weeks cycle [24]. In contrast, the approved cytotoxic doses of azacytidine are associated with a decline of neutrophils in the peripheral blood [36].

- Unchanged, osteolytic 'defect healing' could be observed in RCCC and MM. In CRPC osteoplastic metastases remained stable, also in case of PSA response.

- In mLCH skin lesions $(n=2)$ and severe $\mathrm{mLCH}$ associated bone marrow insufficiency $(n=2)$ resolved, however, following liver failure due to infiltration, the liver function improved with severe defects $(n=1)$, but lesions in the intestine completely resolved $(n=1)$. The boy was 


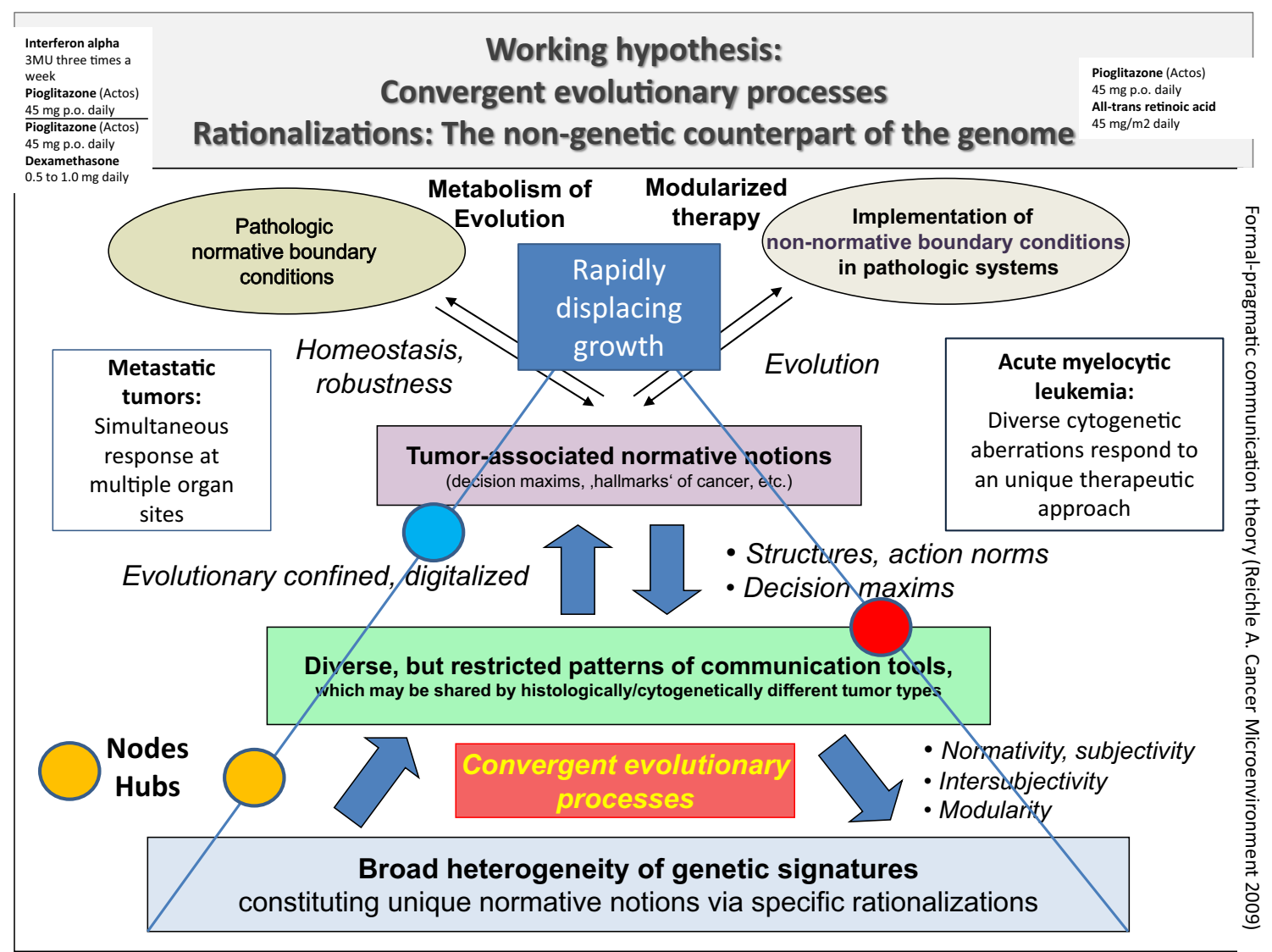

Fig. 4 Simultaneous tumor response at multiple metastatic tumor sites and response of cytogenetically heterogeneous AMLs to a unique therapeutic approach indicates that restricted pattern of communication

originally designated for combined liver and bone marrow transplantation.

- Negative PET scan revealed significant metabolic changes in cHL $(n=3)$ during therapy despite the presence of residual disease in CT scans [25].

- Missing technetium up-take despite the unaltered presence of osteoplastic metastases in CT scan was detected in 6 of 6 PSA responders (CRPC II) [22].

- In MM, hemoglobin levels increased in 4 of $6 \mathrm{pts}>1.0 \mathrm{~g} / \mathrm{dl}$ during the 4 weeks core phase. That means hemoglobin increase could not be due to rapid myeloma clearance in the bone marrow [23].

Dual Transcriptional Regulation Stimulates Globally, Acts Locally: Toxicity Profiles of Schedules Including Dual Transcriptional Modulation are Modest

In CRPC toxicities grade 3 to 4 compare to abiraterone, but no cardiotoxicity occurred. Quality of life measurements during the first 6 months on therapy showed a stabilization of all functions and no impairment compared to pulsed chemotherapy (docetaxel) [22]. tools, particularly rationalizations of hallmarks of cancer, are uniquely accessible with cellular therapies in situ

In RCCC trial I, II reported maximal toxicity was WHO grade 3, predominantly due to hand-foot-syndrome (capecitabine) [20].

AML: Compared with conventional myelosuppressive chemotherapy regimens, treatment with 5-azacytidine, pioglitazone and all-trans retinoic acid was associated with much lower toxicity and could be easily administered in an outpatient setting. The most common adverse events were hematologic toxicities grade 1-4 without the need for platelets or erythrocyte transfusions or administration of growth factors [24].

CHL: Compared with conventional myelosuppressive chemotherapy regimens, or brentuximab-vedotin therapy, the treatment was associated with much lower toxicity and could be easily administered in an out-patient setting without any hospitalization during therapy. Even no grade 3 or 4 hematologic toxicity occurred and there was no need for platelets or erythrocyte transfusions or administration of growth factors despite the heavily pretreatment of the three patients. Also no grade 3 or 4 nonhematologic toxicities were observed. Dose reductions were not necessary [25]. 


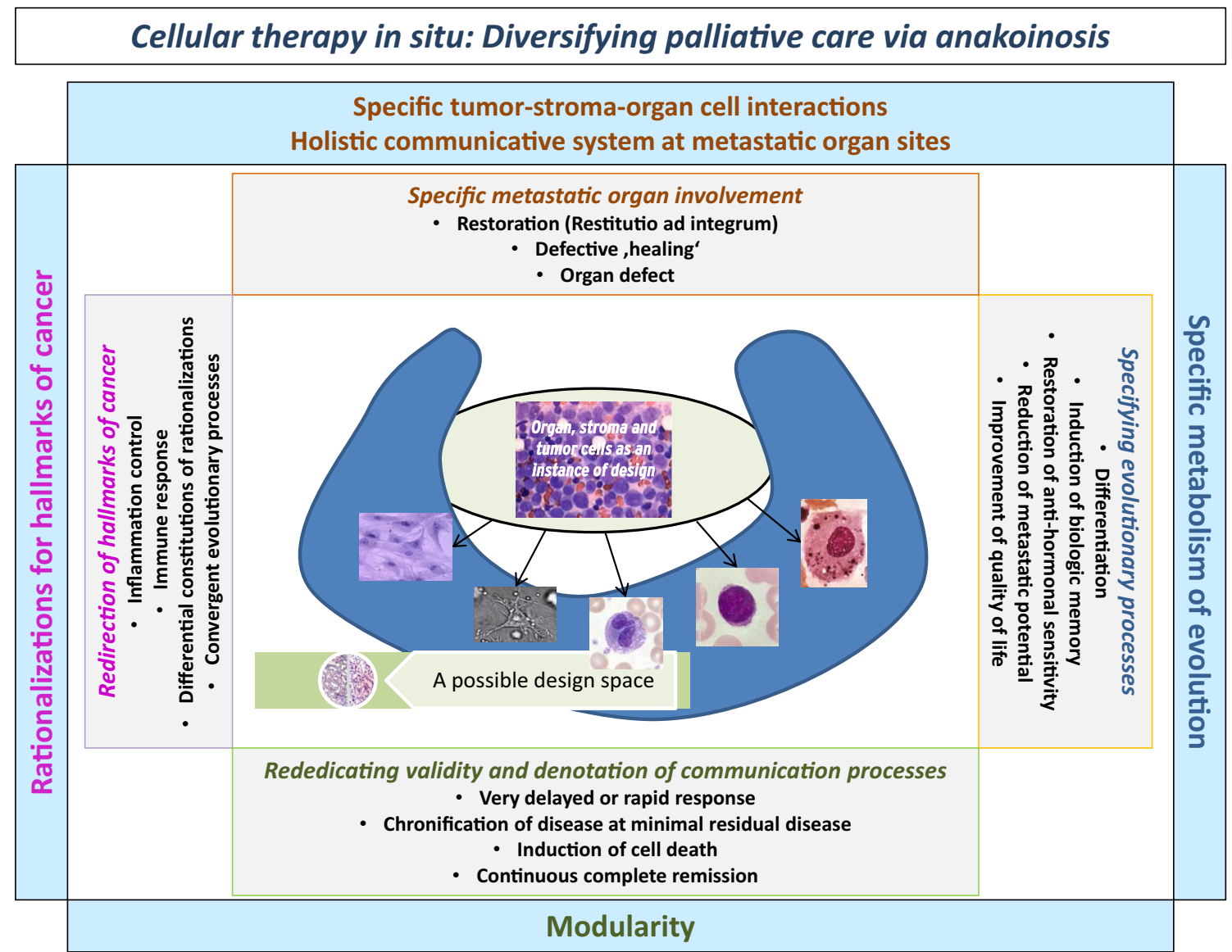

Fig. 5 Cellular therapies in situ get access to the tumor's design space via anakoinosis

MLCH: In the 11 months old boy high fever rapidly resolved after start of cellular therapy in situ including temsirolimus. Maximal toxicity observed was grade 3 hematotoxicity. Due to grade 3 hematotoxicity daily weight adapted trofosfamide doses were reduced in both patients.

MM: Patients experienced no dose-limiting toxicity at both dose levels of lenalidomide (10 or $15 \mathrm{mg}$ daily). All patients continued treatment in the extension phase. Serious adverse reactions observed during follow-up were infections ( $n=6$, Grade 2 NCI-CTCAE toxicity), depressed mood ( $n=1$, Grade 2), osteonecrosis of the jaw and tooth extraction $(n=1)$, and thrombosis during anticoagulation ( $n=1$, Grade 2) [23].

\section{Cellular Therapies In Situ}

Dual Transcriptional Modulation Pioglitazone was used in combination with dexamethasone or all-trans retinoic acid or interferon-alpha.

- In AML the add-on of pioglitazone to all-trans retinoic acid led to a novel behavior of leukemia cells (differentiation, leukemia cell death) and normal hematopoiesis (release of neutrophils in peripheral blood) [24]. In RCCC (RCCC II), the add-on of interferon-alpha decisively improved outcome, based on inflammation control [20].

- Induction of anakoinosis with identical pairs of transcriptional modulators, pioglitazone and dexamethasone (Tables 1 and 2), mediated multifaceted clinical responses in CRPC (CRPC II), cHL, MM and mLCH (Tables 4 and 5). Responses turned out to be heterogeneous in CRPC (CRPC II) (waterfall blot, Fig. 2) [22].

Metronomic low-dose chemotherapy:

- Changing the drug for metronomic low-dose chemotherapy, from capecitabine to treosulfan, improved in a historic comparison both, median PFS and OS from 4.0 to 14.1 months, respectively, in the CRPC I trial, to a PFS of 15.3 months and median OS, which has not been achieved after 3 years (CRPC II trial) [21, 22].

Drug repurposing:

- Imatinib did not add any additional clinical benefit, even in case of scheduled dose escalation (double dose) [22]. 
Table 4 The left column presents the two of four communication tools (the holistic communicative context in the tumor microenvironment andthe tool of rationalizations constituting hallmarks of cancer) and their corresponding constraints, which specify the respective communication processes. The middle column shows the communication technical targets operated by anakoinosis. The right column summarizes therapeutic tools accessible by anakoinosis
Principles for communication- based

therapeutic designs in tumor tissues

and constraints

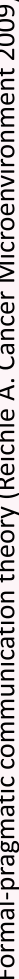

(1) Holistic communicative context in the tumor microenvironment

Tumor-specific constraints:

- Acquired genetic aberrations

Specific communication tools among tumor, stroma, organ cells: Specific pathology, ,social' behavior

- Specific tumor-stroma-organ cell interactions: pathology (homing, dormancy, proliferation, destruction)

(2) The tool of rationalizations constituting hallmarks of cancer

Tumor-specific csonstraints:

- Physical constitution of tumorassociated rationalization processes constituting, hallmarks' of cancer

\section{Convergence of evolutionary} processes: Diverse aberrant (molecular-)genetic pattern support identical rationalizations for hallmarks of cancer

- Specific non-genetic counterpart of the genome

\section{Categories for designing communica- tion tools, i.e., anakoinosis in tumor tissues}

(1) 'Top-down' strategies for targeting the tumors' normativity (e.g. hallmarks)

Redirecting tumor-specific cellular context: Designing therapy response via

- Structures, functions decision maxims (hubs, checkpoints)

Meeting the topology of aggregated action effects: Implementation of nonnormative boundary conditions

(2) Redirection of rationalizations

Evolution-adjusted tumor pahphysiology:

- Shared rationalizations by different histologic tumor types

- Rationalizations are not organ- or histology-dependent

- Rationalizations may be supported by differential cellular tumor compartments and

- diverse acquired genetic pattern

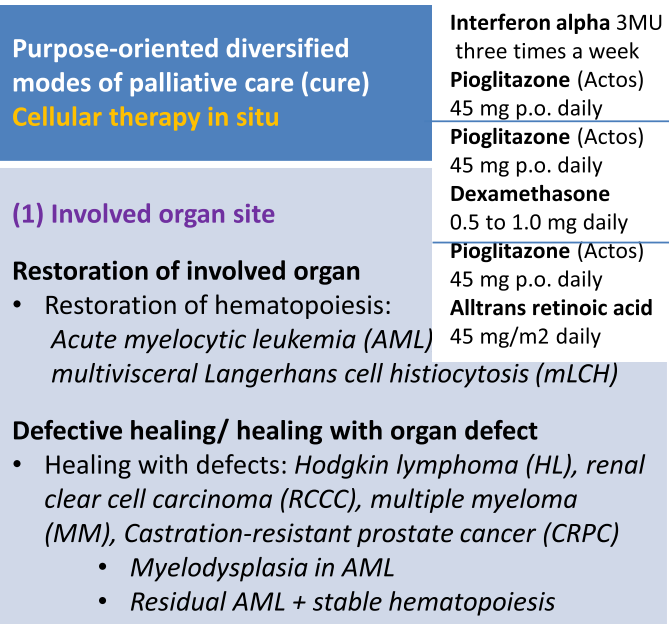

(1) Involved organ site

Restoration of involved organ

- Restoration of hematopoiesis: Acute myelocytic leukemia (AML)

Interferon alpha $3 \mathrm{MU}$ three times a week Pioglitazone (Actos) $45 \mathrm{mg}$ p.o. daily Pioglitazone (Actos)

$45 \mathrm{mg}$ p.o. daily Dexamethasone 0.5 to $1.0 \mathrm{mg}$ daily Pioglitazone (Actos) $45 \mathrm{mg}$ p.o. daily Alltrans retinoic acid multivisceral Langerhans cell histiocytosis $(\mathrm{mLCH})$

Defective healing/ healing with organ defect

- Healing with defects: Hodgkin lymphoma (HL), renal clear cell carcinoma (RCCC), multiple myeloma (MM), Castration-resistant prostate cancer (CRPC)

- Myelodysplasia in AML

- Residual AML + stable hematopoiesis

(2) Targeting rationalizations of hallmarks of cancer

Inflammation control

- C-reactive protein response: $m L C H, M M, R C C C, H L$, Castration-resistant prostate cancer (CRPC)

Immune response (clinically):

- Resolution of lupus erythematodes: CRPC

Differential constitutions of rationalizations

- Differentiation specifically rationalized: $A M L$

- Inflammation specifically rationalized: $m L C H, R C C C$

Convergent evolutionary processes

- Response despite most diverse cytogenetics in AML

- Simultaneous response at multiple organ sites

Addressing genetic and molecular-genetic heterogeneity in metastatic tumors by cellular therapy in situ
- However, either in cHL or in mLCH the add-on of an mTor inhibitor could induce PET negativity and PR (cHL) or continuous, histologically confirmed CR in $\mathrm{mLCH}$ [25].

- Continuing a low-dose IMiD therapy within a cellular therapy in situ after failure of IMiDs, may rescue MM patients $(n=1)$ [23].

- The impact of COX-2 inhibitors could not be evaluated in the present designs of cellular therapies in situ.

Adoptive therapy

- For adopting anakoinotic constellations, drugs with anakoinotic activity profile were selected (drug repurposing); in AML low-dose azacytidine (epigenetic reprogramming) [24], in $\mathrm{mLCH}$ or cHL, mTOR inhibitors (immune modulatory, angiostatic) [25], in MM, lenalidomide (immune modulatory) [23], and in several tumor types COX-2 inhibitors (anti-inflammatory)
(Table 2). Also the chosen cytotoxic drugs for metronomic chemotherapy seem to impact outcome (CRPC I/II).

- Adoptive therapy in an individual patient was successfully used in $\mathrm{mLCH}$ and cHL (Fig. 3), in a patient cohort in RCCC (RCCC II).

\section{Discussion}

\section{Diversified Modes of Palliative Care or Induction of Cure by Cellular Therapy In Situ}

Distant metastasis is the leading cause of cancer mortality. Context-dependently changing validity and denotation of tumor-promoting pathways [19, 30, 31, 37, 38], and genetic heterogeneity at metastatic sites are major reasons for failure of theme-dependent (pathway-,epitope-directed) targeted therapy [39-41]. 
Table 5 The left column presents the two of four communication tools (modular events and the specific metabolism of evolutionary processes) and their corresponding constraints, which specify the respective communication processes. The middle column shows the communication technical targets operated by anakoinosis. The right column summarizes therapeutic tools accessible by anakoinosis

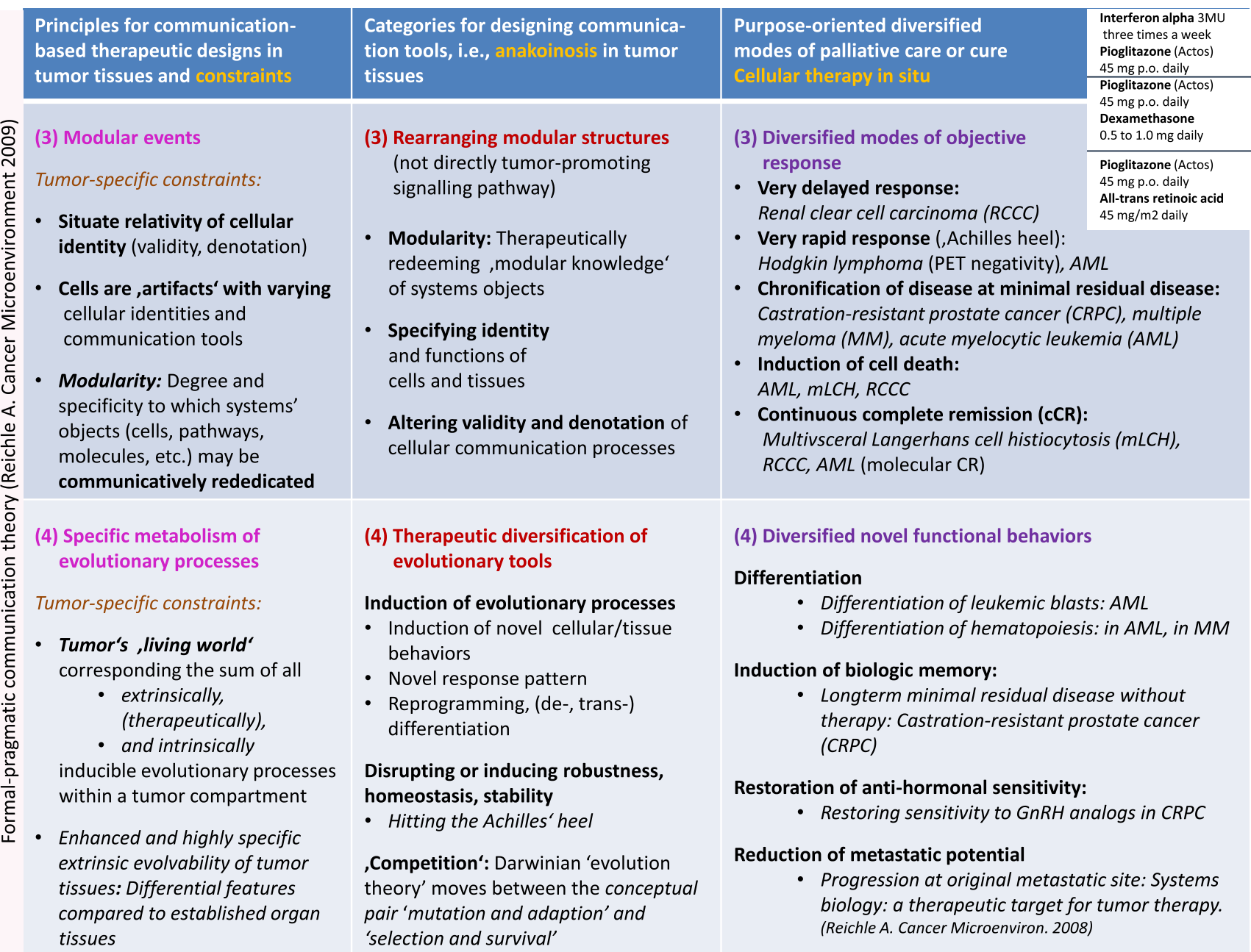

Communicative reprogramming, i.e., anakoinosis, induced by cellular therapies in situ turned out to consistently overcome classic intrinsic, extrinsic resistance, and particularly resistance due to (molecular-) genetic tumor heterogeneity, as indicated by multiple modes of long-term tumor control, even in small series of consecutively treated patients suffering from refractory, metastatic tumor diseases or hematologic neoplasia with quite different histologic origin. Cellular therapies in situ successfully overcome resistance by concertedly redirecting convergent, but differentially organized communication tools (Fig. 4), while been supported by quite different pattern of chromosomal and molecular-genetic aberrations [24, 40, 41].

Induction of anakoinosis in chemorefractory metastatic neoplasia is characterized by diversified response patterns along the trajectory of tumor-specific communication tools. The conceptual introduction and operationalization of communication tools, which allows redirecting validity and denotation of tumor-promoting systems participators (cells, pathways etc.), is the starting point for the therapeutic turnaround from a classic theme-dependent to a communication oriented therapy strategy (Tables 4 and 5) [19].

\section{Anakoinosis in Tumor Tissues: Categories for Designing Communication Tools}

For the first time, to our knowledge, comprehensive categories for designing anakoinosis could be separated (Tables 4 and 5) on the basis of systematic clinical observations during cellular therapies in situ and after withdrawal due to tumor progression or non-oncologic surgical interventions. The summarized principles for communication- based therapeutic designs close the gap, between available results describing communication design on a molecular level in simplistic systems in vitro, for example with transcriptional modulators [11-13, 17], and the clinical observations derived on the scale of complex tissue levels in refractory tumors. 
Anakoinosis describes the therapeutic accessibility of reciprocal communicative interactions among biologic systems participators, i.e., structures (cell compartments, pathways etc.), functions (angiogenesis, immune response etc.) and decision maxims (cellular hubs) via ubiquitously available, and as shown, specifically targetable communication tools (Tables 4 and 5, Fig. 7). The presented multifold therapeutically designed anakoinotic systems stages allow reconsidering what tumor systems have in common, namely targetable, seemingly elusive communication tools. Similar to immune modulating therapies [42], the anakoinotically induced systems stages would not spontaneously develop via natural evolutionary events.

An important observation is that normal organ systems are obviously not as susceptible to anakoinosis as tumor systems (Fig. 5). This is indicated by modest side effects of cellular therapies in situ, even during long-term administration (CRPC II, MM). Vice versa, tumors are downright characterized by anakoinotic accessibility. Anakoinotic response profiles can be now clinically categorized for therapeutically designing communication tools (Tables 4 and 5) [15].

Tumor-associated rationalizations constituting hallmarks of cancer are part of targetable communication tools [18]. Particularly rationalizations for immune response are already systematized: Identical tumor immune responses may be found at primary and metastatic sites [43, 44], and the kind of immune response is predictive for survival [45].

Classic targeted therapies single out specific rationalizations as important targets for tumor control [46, 47]. All these therapies leave out of consideration that rationalizations of hallmarks of cancer may have large variations in their constitution, and are often redundantly organized, such as angiogenesis [7], inflammation [16, 28, 48], and immune response [44-46, 49] etc.

Just specific anakoinosis inducing schedules meet these variations among the tumor-specific tools of rationalizations by adoptive therapy approaches: This tool represents the targetable, communication based non-genetic counterpart of the genome (Tables 4 and 5).

The architectures of communication tools (Tables 4 and 5) or rationalizations for hallmarks of cancer have in common that they may be unrelated to histologic tumor types or clinical stages [44, 45], and - therapeutically decisive - are often similarly organized at primary tumor sites and metastatic lesions (rare mixed responses in RCCC II [16, 44].

Common anakoinotic processes among tumors, unique constitutions of hallmarks of cancer in primary tumors and metastatic sites as well as shared anakoinotic processes within different histologic tumor types [7, 44, 45] support the claim for an evolution-adjusted tumor pathophysiology for

\section{Anakoinosis}
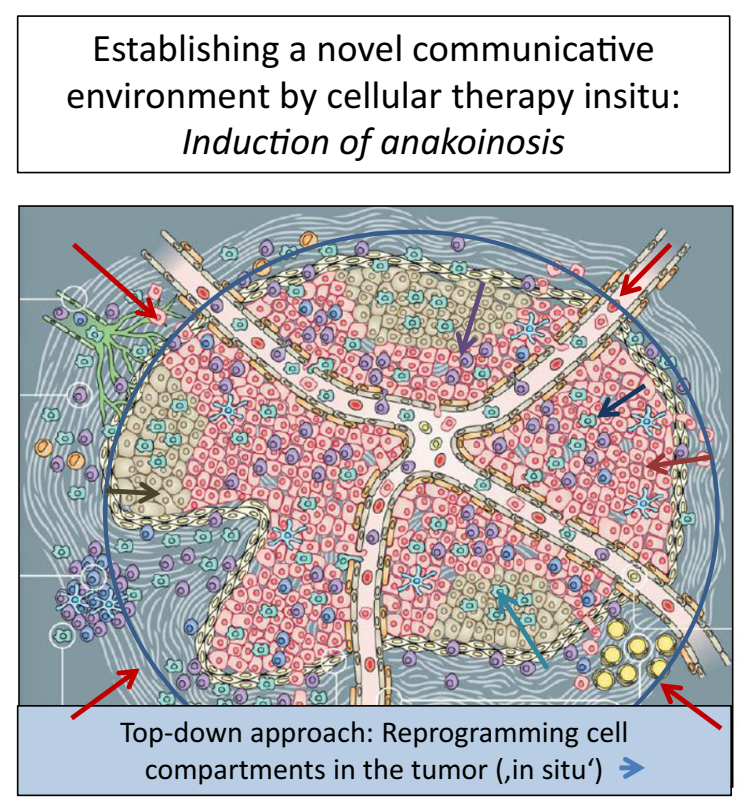
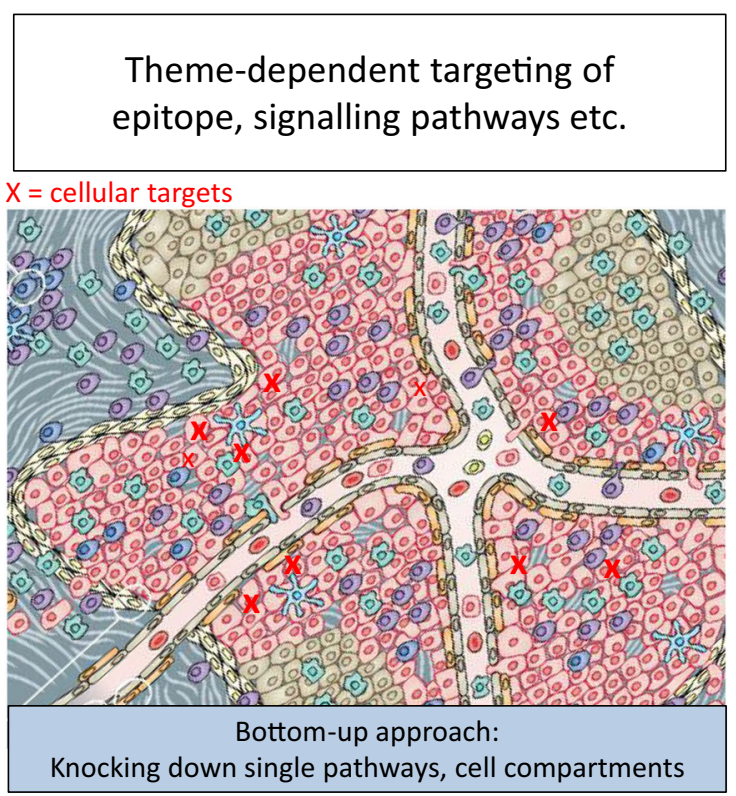

Differential ways to tumor cell death

Anakoinosis: Novel ways for palliative care

Fig. 6 Bottom-up and top-down strategies both redirect and modulate rationalizations constituting hallmarks of cancer, but are using separate techniques, either theme-dependent targets or communicative reprogramming, i.e., anakoinosis 
guiding anakoinotic and rationalization oriented tumor therapies (Fig. 6) [50].

\section{Designing Cellular Therapies In Situ}

The therapeutic elements of cellular therapies in situ are establishing 'on-site' novel boundary conditions, thereby, accomplishing a virtual communicative context for reprogramming tumor systems - importantly, in a reproducible and clinically relevant way (Tables 4 and 5).

Dual transcriptional modulation emerged as pivotal therapeutic instrument for reprogramming tumor systems and for uncovering and therapeutically exploiting basic communication tools (Tables 1 and 2). Therapies designing communication tools equivalently target stromal and tumor cells, which are now considered as holistic communicative system (Fig. 7). Specific anakoinotic processes may be induced - as shown regardless of whether tumors are predominantly consisting of stromal cells, like in cHL, or of tumor cells, like in case of AML (Fig. 7).

Drug Repurposing The paradigmatic shift from low-dose metronomic dosing and considering cancer as targetable communicative system will be given priority in our approach to the selection of drugs for repurposing. The intention is not to look for new anti-proliferative cytotoxic agents or classic targeted therapies that can be used at maximum tolerated doses, the 'magic bullets', but to look for drugs from the available clinical tool that can be used to support the redirection of tumor-specific communication tools. There is a clear rationale for introducing combinations of regulatory acting agents, which concertedly work on multiple communication tools as indicated in Tables 4 and 5. The concerted regulatory activity may even evolve tumor systems for generating novel systems behaviors (Fig. 5).

Many targeted therapies, also those used in the current trials, may be repurposed, as their activity profile is strongly

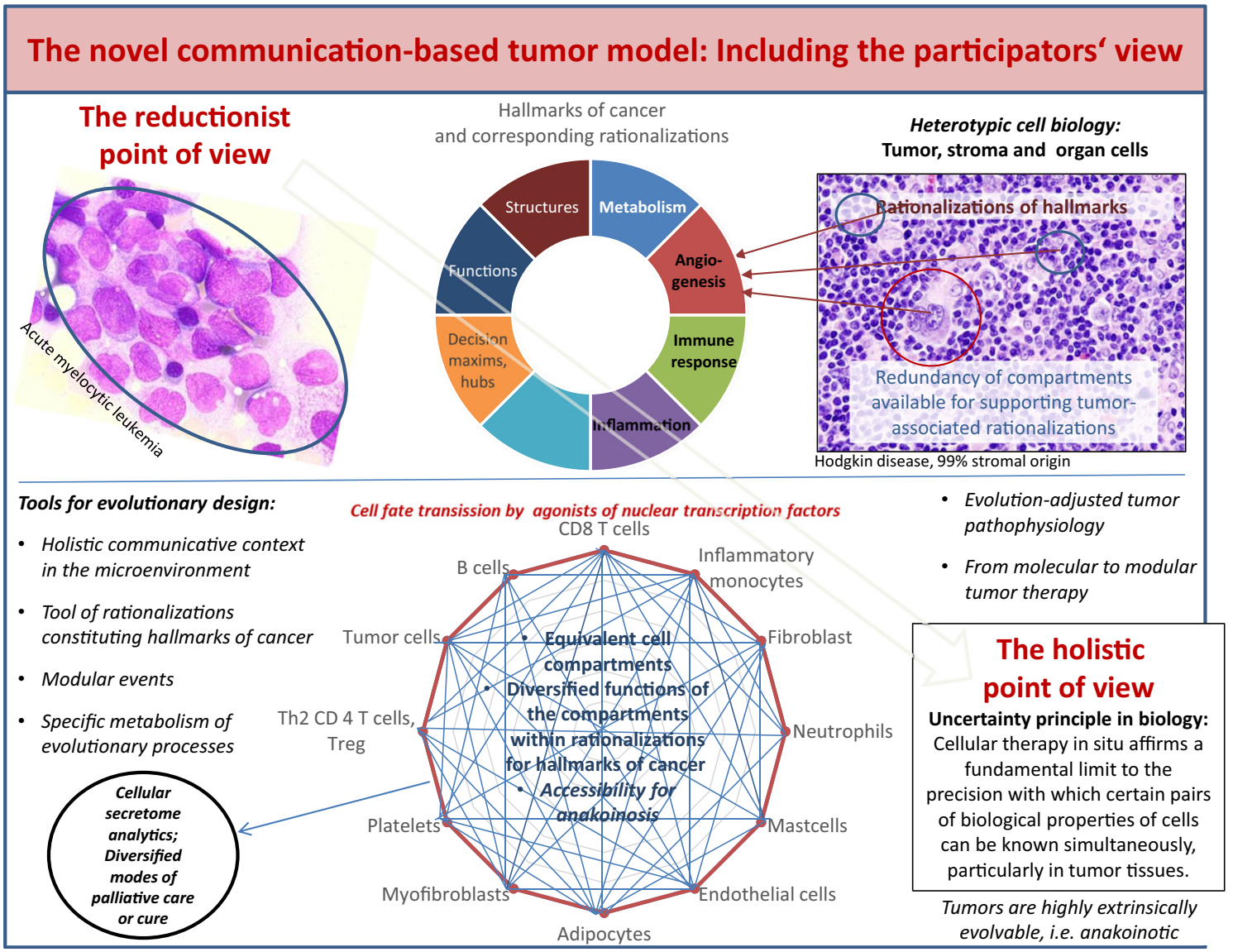

Fig. 7 Anakoinosis inducing regimen may rescue refractory malignancies regardless of whether tumors are predominantly consisting of non-tumor cells, like in $\mathrm{cHL}$, or of tumor cells, like in case of AML. Traditionally, reductionist tumor models are focusing separately on tumor and/or stroma cells ('seed and soil'). Holistic models are aiming at the communicative system, equivalently constituted by tumor and stroma cells. The heterogeneous activity profiles of anakoinosis, even within a single tumor disease, now figures out fundamental limits to the precision with which certain pairs of biological properties in the cell compartments can be predicted simultaneously, particularly in tumor tissues. Comprehending and monitoring cell identities and functions during various systems stages of tumors will be of major interest in future for establishing anakoinosis and should stimulate intensified research in the field of cellular secretome analytics in blood serum or plasma 
dependent on the tumor type and stroma composition, and - as shown by cellular therapies in situ - on the co-regulatory activity profile of the combination partners [9, 51]. In anakoinotic therapy schedules, the sum of single known drug activities may establish a completely novel quality of action in the tumor.

Metronomic low-dose chemotherapy is much better understood from its diverse interactions with rationalizations of hallmarks of cancer, such as immune response and angiogenesis [14] and may support the activity profile of transcriptional modulators $[16,52,53]$. Also the activity profile of low-dose metronomic chemotherapy is strongly dependent on the histologic tumor type or the tumor-specific communication tool, respectively [48].

5-azacytidine at low doses induces differentiation and activation of silenced genes. The clinical effects in non-APL AML patients treated with 5-azacytidine, all-trans retinoic acid and pioglitazone do not emerge in patient treated with the single drugs or as add-on to chemotherapy [54, 55]: Even 5azacytidine at standard dose may be rescued by the triple combination, and patients refractory to standard induction therapy responded with CRm [24].

\section{Principles for Communication- Based Therapeutic Designs in Tumor Tissues and Constraints}

Anakoinotic 'operations' may be summarized as principles for communication- based therapeutic designs in tumor tissues and their corresponding tumor-specific constraints (Tables 4 and 5). Up-to-now the kind of anakoinotic reactivity can be only poorly predicted on the basis of molecular parameters. Therefore, we defined principles for communicationbased therapeutic designs by defining constraints for design. The constraints are characterized by communication specifying key parameters as indicated in Tables 4 and 5.

In contrast to the commonly used reductionist definitions for modularity (the degree to which collective functions of systems participators are insulated from other components and pathways [56]), we use now an exclusive communication-technical definition for modularity (communicative rededication of validity and denotation of systems participators [15]).

On the background of the novel definition and the systematization of communication principles in tumors, therapeutic communication design represents a novel pathophysiologically relevant tool, even for inducing tumor cell death in resistant disease, besides multifold beneficial palliative treatment effects (Tables 4 and 5).

Therapeutically specifiable anakoinotic constellations in metastatic tumors may be integrated in novel systemsbiological models to develop strategies for modifying tumorassociated communication tools with adoptive cellular therapies in situ (Fig. 7).
Therapeutically important is the fact that anakoinotic communication tools may be shared by histologically unrelated tumors [7] and by metastatic sites within an individual tumor disease $[16,44]$ : Anakoinotic response to dexamethasone plus pioglitazone was established in $\mathrm{CHL}, \mathrm{LCH}, \mathrm{CRPC}$, and MM, and to pioglitazone plus all-trans retinoic acid in AML and pre-clinically in breast cancer $[11,24]$. However, the phenotypic expression of anakoinosis among different histologic tumor types is qualitatively different as indicated by characteristic clinical features: The communicative background in the respective tumor specifically determines the phenotypic facets of anakoinosis.

The molecular basis of processes inducing anakoinosis needs to be evaluated further, particularly anakoinotic constellations leading to tumor cell death.

\section{Uncovering Tumor Systems Biology by Anakoinosis}

In future, novel tumor models (Fig. 7) will define communication-technically exploitable resources for promoting anakoinosis with cellular therapies in situ: Top-down - in contrast to bottom-up approaches (Fig. 6) - reconsider communicative prerequisites determining situate validity and denotation of single tumor-promoting pathways or targets, the contingently organized communication tools (Fig. 4), and the uncertainty principle concerning the situate function of cellular tumor compartments (Fig. 7) - as shown for example in the diversified anakoinotic responses in $\mathrm{AML}, \mathrm{mLCH}$ or in the CRPC II trial.

The heterogeneous activity profiles of anakoinosis inducing regimen, even within a single histologically defined tumor disease, now figure out fundamental limits to the precision with which certain pairs of biological properties in cell compartments can be predicted simultaneously, particularly in tumor tissues and different tumor sites. Tumor-associated communicative constellations provided for anakoinosis, should be consecutively analyzed, analytically or empirically at the bench and may be retranslated into new communicative systems interpretations. Thus, the methodology may partially reverse the traditional information flow, which is affected by the predominant transfer from analytical sciences to applied sciences [57].

Comprehending and monitoring cell identities and functions during various systems stages of tumors will be of major interest in future for establishing purposefully anakoinosis and should stimulate intensified research in the field of cellular secretome analytics in blood serum or plasma $[8,58]$.

Differential selection of specific anakoinotic processes for reprogramming tumor cell compartments may offer completely novel possibilities for diversifying therapeutic instruments aiming at long-term tumor control. These promising data with anakoinosis inducing combination therapies in chemorefractory neoplasia warrant further investigation in clinical 
trials. Perspectival, also patients at risk for acquiring tumor diseases could benefit from novel anakoinosis inducing schedules.

Acknowledgments The authors want to thank Barbara Dietl for her support to find an adequate ancient Greek term describing communication by inclusion of the responses of the communication partner, namely 'anakoinosis'.

Open Access This article is distributed under the terms of the Creative Commons Attribution 4.0 International License (http:// creativecommons.org/licenses/by/4.0/), which permits unrestricted use, distribution, and reproduction in any medium, provided you give appropriate credit to the original author(s) and the source, provide a link to the Creative Commons license, and indicate if changes were made.

\section{References}

1. Paterlini-Bréchot P (2014) About seed and soil. Cancer Microenviron 7:91-93

2. Remon J, Majem M (2013) EGFR mutation heterogeneity and mixed response to EGFR tyrosine kinase inhibitors of non-small cell lung cancer: a clue to overcoming resistance. Trans Lung Cancer Res 2:445-448

3. Imielinski M, Berger AH, Hammerman PS et al (2012) Mapping the hallmarks of lung adenocarcinoma with massively parallel sequencing. Cell 150:1107-1120

4. Faber K, Bullinger L, Ragu C et al (2013) CDX2-driven leukemogenesis involves KLF4 repression and deregulated PPAR $\gamma$ signaling. J Clin Invest 123:299-314

5. Hafner C, Toll A, Gantner S et al (2012) Keratinocytic epidermal nevi are associated with mosaic RAS mutations. J Med Genet 49: 249-253

6. Hanahan D, Coussens LM (2012) Accessories to the crime: functions of cells recruited to the tumor microenvironment. Cancer Cell 21:309-322

7. Kallinowski F, Schlenger KH, Runkel S et al (1989) Blood flow, metabolism, cellular microenvironment, and growth rate of human tumor xenografts. Cancer Res 49:3759-3764

8. Pitteri SJ, Kelly-Spratt KS, Gurley KE et al (2011) Tumor microenvironment-derived proteins dominate the plasma proteome response during breast cancer induction and progression. Cancer Res 1:5090-5100

9. Bundscherer A, Hafner C (2010) Breathing new life into old drugs: Indication discovery by systems directed therapy. In: Reichle A (ed) From molecular to modular tumor therapy. Springer, Berlin, pp 483-503

10. Pantziarka P, Bouche G, Meheus L et al (2014) The repurposing drugs in oncology (ReDO) project. Ecancer Med Sci 8:442

11. Papi A, De Carolis S, Bertoni S et al (2014) PPAR $\gamma$ and RXR ligands disrupt the inflammatory cross-talk in the hypoxic breast cancer stem cells niche. J Cell Physiol 229(11):1595-1606

12. Glass CK, Ogawa S (2006) Combinatorial roles of nuclear receptors in inflammation and immunity. Nat Rev Immunol 6:44-55

13. Molecular cross-talk between nuclear receptors and nuclear factorkB. Beck IME, Haegeman G, De Bosscher KA. Reichle A (ed.) From molecular to modular tumor therapy. Springer, Berlin, 191242

14. Emmenegger U, Chow A, Bocci G (2010) The biomodulatory capacities of low-dose metronomic chemotherapy: Complex modulation of the tumor microenvironment. In: Reichle A (ed) From molecular to modular tumor therapy. Springer, Berlin, pp 243-262
15. Reichle A, Hildebrandt GC (2009) Principles of modular tumor therapy. Cancer Microenviron 2(Suppl 1):227-237

16. Reichle A, Vogt $\mathrm{T}$ (2008) Systems biology: a therapeutic target for tumor therapy. Cancer Microenviron 1:159-170

17. Mendoza-Parra MA, Gronemeyer H (2013) Genome-wide studies of nuclear receptors in cell fate decisions. Semin Cell Dev Biol 24: 706-715

18. Reichle A. Including rationalizations of tumor-associated normative notions in pathophysiologic considerations: Communicationtheoretical implications. Reichle A (ed) Evolution-adjusted tumor pathophysiology. Springer, Berlin, 289-299

19. Reichle A, Gerner C, Haegeman G (2013) Criticizable claims for the validity of communication acts in biological systems: Therapeutic implications in cancer. Reichle A (ed) Evolutionadjusted tumor pathophysiology. Springer, Berlin, 169-187

20. Reichle A, Grassinger J, Bross K et al (2007) C-reactive protein in patients with metastatic clear cell renal carcinoma: an Important biomarker for tumor-associated Inflammation. Biomark Insights 1:87-98

21. Walter B, Rogenhofer S, Vogelhuber M et al (2010) Modular therapy approach in metastatic castration-refractory prostate cancer. World J Urol 28:745-750

22. Vogelhuber M, Feyerabend S, Stenzl A, et al. (2014) Biomodulatory treatment of patients with castration-resistant prostate cancer: A phase II study of imatinib with pioglitazone, etoricoxib, dexamethasone and low-dose treosulfan. Cancer Microenviron

23. Reichle A, Hart C, Grube M et al. (2012) Anti-inflammatory, immuno-modulatory and angiostatic treatment as third-line therapy for multiple myeloma (MM) - a combined treatment setting of lenalidomide with pioglitazone, dexamethasone and low-Dose treosulfan (phase I/II) Blood (ASH Annual Meeting Abstracts) 120:5029

24. Thomas S, Schelker R, Klobuch S et al (2015) Biomodulatory therapy induces complete molecular remission in chemorefractory acute myeloid leukemia. Haematologica 100(1):e4-e6

25. Ugocsai P, Wolff D, Menhart K (2015) Biomodulatory metronomic therapy induces PET negative remissionin chemo- and brentuximab-refractory Hodgkin disease. Br J Haematol. doi:10. 1111/bjh. 13480

26. Reichle A, Vogt T, Kunz-Schughart L et al (2005) Antiinflammatory and angiostatic therapy in chemorefractory multisystem Langerhans' cell histiocytosis of adults. Br J Haematol 128: 730-732

27. Reichle A, Vogelhuber M, Vogt T et al. (2013) Long-term results of combined modularized, immune-modulatory, angiostatic, and antiinflammatory therapy in systemically pre-treated multi-systems Langerhans cell histiocytosis. Reichle A (ed) Evolution-adjusted tumor pathophysiology. Springer, Berlin, 35-45

28. Pahler JC, Tazzyman S, Erez N et al (2008) Plasticity in tumor promoting inflammation: impairment of macrophage recruitment evokes a compensatory neutrophil response. Neoplasia 10:329-340

29. Vogt $\mathrm{T}$, Coras B, Hafner $\mathrm{C}$ et al (2006) Antiangiogenic therapy in metastatic prostate carcinoma complicated by cutaneous lupus erythematodes. Lancet Oncol 7:695-697

30. Gerlinger M, Rowan AJ, Horswell S et al (2012) Intratumor heterogeneity and branched evolution revealed by multiregion sequencing. N Engl J Med 366:883-892

31. Vogelstein B, Papadopoulos N, Velculescu VE et al (2013) Cancer genome landscapes. Science 339:1546-1558

32. Tilg H, Vogel W, Dinarello CA (1995) Interferon-alpha induces circulating tumor necrosis factor receptor p55 in humans. Blood $85: 433-435$

33. Inoue K, Kawahito Y, Tsubouchi Y et al (2001) Expression of peroxisome proliferator-activated receptor gamma in renal cell 
carcinoma and growth inhibition by its agonists. Biochem Biophys Res Commun 287:727-732

34. Gerber SA, Pober JS (2008) IFN-alpha induces transcription of hypoxia-inducible factor-1alpha to inhibit proliferation of human endothelial cells. J Immunol 181:1052-1062

35. Berthold DR, Pond GR, Soban F et al (2008) Docetaxel plus prednisone or mitoxantrone plus prednisone for advanced prostate cancer: updated survival in the TAX 327 study. J Clin Oncol 26:242-245

36. Pleyer L, Burgstaller S, Girschikofsky M et al (2014) Azacitidine in 302 patients with WHO-defined acute myeloid leukemia: results from the Austrian Azacitidine Registry of the AGMT-Study Group. Ann Hematol 93:1825-1838

37. Luatti S, Castagnetti F, Marzocchi G et al (2012) Additional chromosomal abnormalities in Philadelphia-positive clone: adverse prognostic influence on frontline imatinib therapy: a GIMEMA Working Party on CML analysis. Blood 120:761-767

38. Yeung WWS, Ho MKC, Wong YH (2010) Functional Impacts of Signal Integration: Regulation of inflammation-related transcription factors by heterotrimeric $\mathrm{G}$ proteins. Reichle A (ed) From molecular to modular tumor therapy. Springer, Berlin, 161-189

39. Almendro V, Kim HJ, Cheng YK et al (2014) Genetic and phenotypic diversity in breast tumor metastases. Cancer Res 74:13381348

40. Gerlinger M, Rowan AJ, Horswell S et al (2012) Intratumor heterogeneity and branched evolution revealed by multiregion sequencing. N Engl J Med 366:883-892

41. Yegnasubramanian S, Haffner MC, Zhang Y et al (2008) DNA hypomethylation arises later in prostate cancer progression than $\mathrm{CpG}$ island hypermethylation and contributes to metastatic tumor heterogeneity. Cancer Res 68:8954-8967

42. Galluzzi L, Vacchelli E, Bravo-San Pedro JM et al (2014) Classification of current anticancer immunotherapies. Oncotarget 5:12472-12508

43. Tosolini M, Kirilovsky A, Mlecnik B et al (2011) Clinical impact of different classes of infiltrating T cytotoxic and helper cells (Th1, th2, treg, th17) in patients with colorectal cancer. Cancer Res 71: 1263-1271

44. Giraldo NA, Becht E, Remark R et al (2014) The immune contexture of primary and metastatic human tumours. Curr Opin Immunol 27:8-15

45. Galon J, Costes A, Sanchez-Cabo F et al (2006) Type, density, and location of immune cells within human colorectal tumors predict clinical outcome. Science 313:1960-1964s
46. Ansell SM, Lesokhin AM, Borrello I et al (2015) PD-1 blockade with nivolumab in relapsed or refractory Hodgkin's lymphoma. N Engl J Med 372:311-319

47. Vasudev NS, Reynolds AR (2014) Anti-angiogenic therapy for cancer: current progress, unresolved questions and future directions. Angiogenesis 17:471-494

48. Reichle A and Hildebrandt GC (2010) The comparative uncovering of tumor systems biology by modularly targeting tumor-associated inflammation. Reichle A (ed) From molecular to modular tumor therapy. Springer, Berlin, 287-303

49. Khandelwal N, Breinig M, Speck T et al (2015) A high-throughput RNAi screen for detection of immune-checkpoint molecules that mediate tumor resistance to cytotoxic T lymphocytes. EMBO Mol Med 7:450-463

50. Reichle A (ed) (2013) Evolution adjusted tumor pathophysiology. Springer, Berlin

51. Reichle A. Biomodulatory therapy approaches in renal clear cell carcinoma: A perspective (2013) Reichle A (ed) Evolutionadjusted tumor pathophysiology. Springer, Berlin, 91-100

52. Reichle A, Vogt T, Coras B et al (2007) Targeted combined antiinflammatory and angiostatic therapy in advanced melanoma: a randomized phase II trial. Melanoma Res 17:360-364

53. Meyer S, Vogt T, Landthaler M (2009) Cyclooxygenase 2 (COX2) and Peroxisome Proliferator-Activated Receptor Gamma (PPARG) Are Stage-Dependent Prognostic Markers of Malignant Melanoma. PPAR Res 2009:848645

54. Krug U, Koschmieder A, Schwammbach D et al (2012) Feasibility of azacitidine added to standard chemotherapy in older patients with acute myeloid leukemia-a randomised SAL pilot study. PLoS ONE 7:e52695

55. Schlenk RF, Fröhling S, Hartmann F et al (2004) Phase III study of all-trans retinoic acid in previously untreated patients 61 years or older with acute myeloid leukemia. Leukemia 18:1798-1803

56. Hartwell LH, Hopfield JJ, Leibler S et al (1999) From molecular to modular cell biology. Nature 402(6761 Suppl):C47-C52

57. Reichle A, Hildebrandt GC (2010) Uncovering tumor systems biology by biomodulatory therapy strategies. Reichle A (ed) From molecular to modular tumor therapy. Springer, Berlin, 287-303

58. Paulitschke V, Kunstfeld R, Gerner C. Secretome proteomics, a novel tool for biomarkers discovery and for guiding biomodulatory therapy approaches. Reichle A (ed) From molecular to modular tumor therapy. Springer, Berlin, 405-431 